\title{
Meeting with the Depicted Other
}

\author{
Marge Paas \\ Tallinn University
}

\begin{abstract}
The main aim of this article is to describe the intersubjective relationship between the observer and the subject depicted in a work of art. More precisely, I am interested in the observer's imagination as it is manifested in this relationship. I argue that every act of empathy involves the imagination, but the act of imagination is never understood as an act of empathy. This article will take a new approach towards the perception of a work of art and challenges the traditional notion of empathy as "looking into," "looking in," or "seeing-in." I describe the experience of empathy as a lived experience, where I understand it as a type of intentional act that is distinct from imagination; meanwhile, I show that the imagination plays a role in the empathetic experience of the work of art. How? I understand this situation as one that brings the observer into a new reality, an intersubjective mode of being where she finds a better understanding of her own (as an observer) inner world. I wish to argue that empathy gives a new dimension to experience, where being "here" becomes being "there." Empathy is in fact a special form of meeting the Other. In the case of a work of art, we do not meet the Other as a person who lives their daily life like everyone else; instead we have an independent empathetic experience of the world, taking place within the work of art, in relation to the depicted subject. The nature of empathy is that it enables the observer to enter the deepest intimacy of the work of art and dwell inside it. This depends solely on the observer on how open they are to this world and how much it coincides with the observer's will, as she always retains limitless freedom when interpreting a work of art.
\end{abstract}

Keywords: empathy, aesthetics, image, spiritual subject

\section{The Notion of Empathy}

Empathy is a lived experience that is never experienced individually; it is an act of experience that remains in the common sphere of experience of two individuals. But in the case of a work of art, the problem of empathy becomes more complex due to the peculiar ontology of the depicted subject. How is it possible to experience empathy in relation to a subject that is depicted in a work of art but not present in a psycho-physical body, one which appears as a fantasy (image) body? For example, if we mentally follow the person who depicts or imagines her, her feelings are reflected in us as live, or as alive. For example, I may read a book and I have a feeling of empathy when following the narrative. There is no real individual, but during my reading something appears in my consciousness as the character a fantasy body and I perceive the character as a person. Or I go to a gallery and I see a woman depicted in a painting, and I sense her moods and her emotions. The character and the depicted woman do not have a body or living body, and the depicted subject is not the real subject, the inner

Marge Paas, Ph.D., School of Humanities, Tallinn University, Estonia; main research field: Phenomenology.

This research was supported by EU DoRa program activity no. T8 "Participation of Young Researchers in the International Circulation of Knowledge". SA Archimedes, Estonia. 
world of whom can be reached in the experience of empathy and could be "behind" the empirically-perceivable act of expression. This imaginary or depicted inner world is not created by the artist but by the observer (in her flow of consciousness). The author of the work of art, the artist, merely creates the expression of the depicted subject. So the observer sees the perceived object, the work of art, and sees in the work of art the subject, which appears in the observer's consciousness. But it is important to understand that the observer is always a psycho-physical spiritual subject (EGO subject) who has the possibility of feeling empathy with the perceived depicted subject (the Other, depicted EGO) in work of art, because I, the act of empathy, do not only take place in the observer, but on a human spiritual level which I clarify later in this article.

And the situation is all the more complicated since the depicted subject henceforth the Other does not have a real body (Körper). However, the observer can perceive the Other's body as a construction created by her own consciousness and thus seen as lived body (Leib). The Other can be seen corporeally because the observer's consciousness creates the re-presentation of the subject as that of a psycho-physical subject. This is the subject that always appears corporeally in the experiential sphere of the observer and which is always seen as a person.

The reason why the observer can perceive the Other (the depicted subject), which is created by her own stream of consciousness, is because the subject appears to the observer aesthetically. The Other is constructed as a person and perceived as an aesthetic subject in the observer's imagination. This situation can be illustrated by looking at Michelangelo's Pietà, in which the Virgin Mary is holding her executed Son. The observer sees the female figure as Mary, who appears as a person. She is perceived as Mary, mother of God, but the observer perceives not only the image of St. Mary, but also the expressive body, which seems to have feelings, perceived as a living body (through the act of imagination). The work of art carries with it a mode of perception that causes the observer to be absorbed in feelings that reflect into her during the experience. Such a description ensures that the observer has created the depicted subject as if it were a person.

Edmund Husserl was interested in this approach when formulating his image consciousness theory, where he also presented three forms that could describe the observer's experience of fantasy: "as it were," "as if," and "quasi-." I would like to note that Edmund Husserl's Phantasy, Image Consciousness, and Memory (Phantasie, Bildbewusstsein, Erinnerung) is a complex study of fantasy, memory, image, and aesthetic consciousness, which he wrote between 1898 and 1925. And if one wants to understand empathy in relation to fictive subjects, objects of fantasy, and the depicted person, one cannot dismiss Husserl's theory of image consciousness, because "as if," as I mentioned previously, is the foremost indicator of how a person that belongs to the observer's world of imagination appears in her consciousness. And it is precisely the observer's fantasy that enables the subject to be present in the world of imagination. ${ }^{2}$ There is also another dimension to perceiving the Other. Husserl distinguishes two situations in which the observer either observes a person in a photograph or the depicted person is portrayed in an artistic manner. If we see a friend in a photograph (in the regular way), then the photograph is the medium. ${ }^{3}$ However, if we were to observe this photograph in an art gallery as a work of art, then the depicted person would appear to the observer through aesthetic contemplation and the object of the photograph would be a representation. In the first case, there is no aesthetic image, but in the second case, there is an aesthetically-perceived image, or an image object. It should also be noted that such aesthetic contemplation can be compared to transcendental reduction, which is not described by Edmund Husserl along with his notion of image consciousness, but later, in 1931, in Cartesian Meditations (Méditations 
cartésiennes), where he refers to: parenthesizing (Klammer setzen) of the entire Objective world and all the other (including depiced EGO) Objectivities. ${ }^{4}$ This means that both the observer and the depicted subject are parenthesized in the observer's consciousness. It is my clarification how the depicted subject will be as the Other person in my consciousness and how we are together in the same horizon after parenthesize. The Other has been created as Other subject in my consciousness and I "see" his/her feelings.

\section{The Question of Primordiality and Non-primordiaity}

Edmund Husserl's assistant Edith Stein (1891-1942), who is among the most interesting female philosophers in the field of phenomenology in the 20th century, was interested in empathy and found that as lived experience it had to be questioned in terms of primordiality (Originarität) because it concerned an act that was primordial as present experience while non-primordial (Nicht-originarität) in content. ${ }^{5}$ She also claimed that empathy was not a perception, a fantasy, or a memory. Instead, empathy is a kind of act of perceiving sui generis. ${ }^{6}$ She explained that no one prohibited the observer from imagining another person, because the body appeared "as if" it were a lived body (in this case the imagined body can also be understood as the Other, because it is recognizably depicted as the Other similar to the observer's body). Stein offers an example of how "I" can be in room and I imagine myself standing in another part of the room. In this case, "I" objectifies my body as a fantasy body in this perceived room. This very same fantasy body is likewise a presented object in the observer's perception. ${ }^{7}$ The observer creates this fantasy body based on their own physical body, ${ }^{8}$ which means that they are able to perceive bodily given-ness that is not based solely on an image, but also on fantasy similarly to the way in which an observer can perceive a fictional character in a literary work or a hero in a novel; they can "see" them as similar to themselves. Now, coming back to the question of primordiality, when I produce a fantasy world during the reading, I am this fantasized world in a primordial sense; but when I am living this fiction in novel, it is given to me in a non-primordial way. In the same way, I can experience a fictional character's emotions that are lived in my inner world in a non-primordial way, which gives me a stream the emotions that have been lived empathically. I understand this situation since I am no longer turned towards the content but to the object of that content; I am the subject of the content, in the original subject's place. ${ }^{9}$ What is also important for Stein is to understand empathy as a certain kind of "seeing,"10 as an observer can see sadness ${ }^{11}$ radiating from the body of another person standing before them. This form of seeing is not itself an empathy, to be clear, it is perception, an act of the observer's imagination, which is a condition for empathy but not empathy in itself. Similarly the observer sees the depicted subject that actually appears to her not only as a fantasy body but in content as expressiveness: The observer sees the body as an expressive body, along with its imagined feelings that can turn into empathetic feelings inside her. This situation can be illustrated with the following example. Take an observer looking at a painting of a crying woman. The observer can see a person, a woman, along with her expressive qualities. Her whole body carries the feelings that appear inside the observer. The sadness that the observer sees in the painting is experienced as an event of sadness perceived from the work of art, meaning that the observer herself is not sad it is "foreign" (Fremdes) sadness. Again, we face the question of primordiality. But this lived sadness can cause the observer to experience a mood that also creates a feeling of sadness. If the observer reaches such an emotional state, then empathy has occurred in relation to the depicted subject. It is interesting to note that this feeling can be experienced as something real and true. 


\section{Empathy and Aesthetic Contemplation}

The way that the object appears to the observer is a form of intentionality, meaning the observer's intentionality towards the work of art as an intentional object. If there was no intentionality, the observer could not be open to the world of the work of art. As such, intentionality proves that the work of art is perceivable aesthetically.

Intentionality, with its specific form of orientation, it brings the observer out of her "self" and invites her to move towards the object of intentionality. The observer is open to the world of her imagination. Similarly, when meeting Michelangelo's Pietà, the observer directs her consciousness towards the Pietà as an intentional object, and if there is a common intersubjective horizon, then the observer recreates the depicted person as one who can be empathetically experienced. The Pietà is not just a piece of stone; it is a whole entity or a world, accessible to everyone. Hence, empathy towards depictions, fictive persons, or objects of fantasy cannot be understood as a methodological conflict. The example of Michelangelo's masterpiece confirms that it is possible to experience empathy towards a work of art. But this empathic relationship can take place only on the condition of intentionality and openness to the work of art, which allows the observer's spiritual personal (Geistiger personen) structure to be open in this way. ${ }^{12}$ After what the observer feels not as if the work of art has overtaken their inner world, but instead that she is part of the work of art, as if she is the subject of the content in the depicted subject's place, the observer feels that she is like the depicted subject in the work of art and feels empathic towards the emotions that are depicted in the work of art she "sees" the depicted feelings and lives non-primordially in the inner world of these emotions. And even after having experienced the work of art empathetically, the sense of this is so strong that the perceived object becomes alive and almost accompanies the observer on leaving the perceived placed (the gallery, say), covertly walking next to her or secretly observing her.

Thus, I wish to argue that empathy enabled by aesthetic contemplation can be so strong and shake the spiritual dimension of the observer so much that it can accompany the observer for a long time afterwards. For example, if the observer has been affected by a film very strongly, on the following she might still sense pictures, emotions, and characters from the film inside her consciousness and as such the validity of an empathetic experience is proven.

\section{Empathy as a Question of Subjectivity}

The observer can never be utterly open to the Other and it is important to note that meeting the depicted Other in the world of imagination is always an incomplete experience. Every new encounter is a new event in the observer's inner world. She must be open to the Other, but never fully perceived which is an important notion for the objectivity of meaning in relation to the artistic object.

Empathy towards the depicted subject cannot be understood as simply seeing someone in a picture with depicted feelings. It cannot be understood as meeting a stranger either, since in empathy the meeting of oneself is always presented in meeting the Other. If this is understood as the spiritual "I," who is subject to the experience of empathy while observing a work of art, then lived experience does indeed open up a spiritual and creative dimension in the observer. Empathy enables the observer to understand herself as an individual. Therefore, empathy is a question of subjectivity in its most complete sense. The observer that empathetically interprets a work of art expresses her own judgments of taste, which are manifested through empathy. The aim 
of this article is not to find an alternative, in empathy, to a Kantian critique of judgments of taste, but to present a new form of aesthetic experience that is apperceived in a person, and to do this such that an experiencing subject can describe an empathetic feeling as something aesthetic. Such an analysis demonstrates that Husserl and Stein were close to discovering something important about the making of aesthetic judgments of taste, where empathy is a means to such aesthetic expression. This is an important question for future research.

The French philosopher Mikel Dufrenne (1910-1995), who identified the concept of empathy in aesthetics thought that the work of art was always "quasi-subject," in Husserl's terminology. But he understands "quasi" as an empathic relation analogue to an interpersonal relationship. ${ }^{13}$ He looks empathy in his Phenomenologie de l'experience esthetique (1953), where he mentions fictive bodies, psycho-physical fictive subjects that have their own spiritual structure just like the observer. This means that the Other is an aesthetic object who reveals herself as an object in expression; the observer sees this affectivity in the Other's expression. Now, Dufrenne found this similar to an endless infinity in perceiving the Other, and what is in aesthetic conditions possible for observer to perceive aesthetically what is also part making the aesthetic judgement of taste being empathically experienced (lived through) the Other.

\section{Feeling Beauty and the Feeling of Beauty}

In the next section, I want to describe the experience that the observer lives through, for example her "experience of beauty." If she is reduced to the empirical world, mentioned above, the observer is what is known as "co-given" with the Other and through aesthetic contemplation has an experience of empathy with the Other. Now, this "empathic being" is lived as something beautiful. I would like an example for clarification from Stein. According to Stein, beauty is: (a) integrity or perfection; (b) due proportion or harmony; and (c) clarity. ${ }^{14}$ She adds that light (physical light) enables us to see beauty, but that there is also a brilliant light that touches our soul. In order to truly experience beauty, Stein thinks that we have to experience intellectual beauty and spiritual beauty together, which represent sensuous beauty. As such, beauty cannot be treated as a characteristic that belongs to the perceived object. Stein bases her approach to transcendental beauty on the philosophy of Thomas Aquinas, and argues that beauty should be treated as knowledge. ${ }^{15}$ Discussing beauty, Stein no longer examines the observer who experiences beauty, but presumes that the perceived psycho-physical spiritual subject is where the knowledge of "beauty" originates.

If the observer experiences beauty when looking at a painting, are they experiencing empathetic beauty or perceived beauty? I argue in this article that the answer lies in the term "beauty" and the observer's judgment of taste. If the observer is looking at a person who has been beautifully depicted in a portrait, then this beauty is revealed to the observer as an aesthetic experience and it assures the observer's judgment of taste on beauty. However, if the observer looks at the portrait painting, which results in the observer being immersed in the world of the work of art, and becomes the beautifully portrayed woman in an environment where the whole natural world is reduced; if the feeling of beauty or joy arises in the observer while enjoying the work of art and having become one with the depicted subject; and if the observer feels "as if" they were there themselves instead of the depicted woman, in the same image space, in a silent conversation with them, then it can be said that the observer has experienced empathetic emotions and has felt, inside them, sensuous beauty.

\section{Conclusion}

I note that different theories and different disciplines approach empathy in different ways. Does the inner 
world of the observer offer a challenge to aesthetics? And is the experience of empathy towards a depicted subject a philosophical problem? This article has shown that empathy as a lived experience enables a perception of the Other that can be located in the world of the imagination, and that the content of an empathetic aesthetic experience is even more challenging and interesting especially when the imagination and judgments of taste are involved. I have questioned how it works in relation to the observer's spiritual level and her feeling sensuous beauty in her own inner self. This investigation has demonstrated that the experience of empathy can be treated as something truthful, where the world of imagination is approached as something objective; and that the experience of empathy is a form or manifestation of aesthetic experience that involves intentionality. I have also shown that the acts of imagination and empathy are distinct.

This article does not explain the theory of mind and Peter Goldie's emotional theory, which is worth to read, but describes the phenomenological relationship between the observer and depicted Other and this method is capable of discovering a new form and principle of inquiry.

The final thing to note is that in this condition, empathy as the observer's individual lived experience comes down to a question of the her own phenomenological structures and takes place on her own spiritual level. It gives her an understanding not only of the work of art, but of her inner self, her creativity, and enables her to understand the world especially in terms of what I understand as human spirituality.

\section{Notes}

1. Edmund Husserl. Phantasy, Image Consciousness, and Memory. Trans. John B. Brough. Springer, Dordrecht, 2005, 33-34.

2. Ibid., 40.

3. Ibid., 56.

4. Edmund Husserl. Cartesian Meditations: An Introduction to Phenomenology. Trans. Dorion Cairns. Martinus Nijhoff Publishers: The Hague, Boston, London, 1982, 99.

5. Edith Stein. On the Problem of Empathy. Washington: ICS Publications, 1989, 10.

6. Ibid., 11.

7. Ibid., 47.

8. Ibid., 47.

9. Ibid., 10.

10. This refers to certain kind of seeing, meaning it has been lived and understood as a flow of experience in order to distinguish seeing from just taking a look. It is more precise to write "seeing" here, which presupposes an experience of the past and the future in the sense of one flow of experience.

11. Edith Stein. On the Problem of Empathy. Washington: ICS Publications, 1989, 68.

12. Stein characterized the spiritual as intellectual. She explained in her book Finite and Eternal Being that we need to observe the activity of spirit, and for example, the knowledge of love, or beauty is the result of the spiritual activity.

13. Andrea Pinotti. "Empathy." Handbook of Phenomenological Aesthetics. Springer Science+Business Media B.V., 2010, 96.

14. Edith Stein. Finite and Eternal Being. Trans. Kurt F. Reinchard. ICS Publications, Washington, D.C., 2002, 322.

15. Ibid., 321.

\section{Works Cited}

Andrea, Pinotti. "Empathy." Handbook of Phenomenological Aesthetics. Springer Science+Business Media B.V., 2010. 96.

Edmund, Husserl. Phantasy, Image Consciousness, and Memory. Trans. John B. Brough. Springer, Dordrecht, 2005. 33-34.

---. Cartesian Meditations: An Introduction to Phenomenology. Trans. Dorion Cairns. The Hague, Boston, London: Martinus Nijhoff Publishers, 1982. 99.

Edith, Stein. On the Problem of Empathy. Washington: ICS Publications, 1989.

---. Finite and Eternal Being. Trans. Kurt F. Reinchard. Washington: ICS Publications, 2002. 322. 